\title{
Effects of phosphorylation of chrysotile on pleuropulmonary fibrogenicity and carcinogenicity
}

\author{
H Daniel, A Wastiaux, P Sébastien, R Bégin
}

\begin{abstract}
As well as fibre size, fibre chemistry is a determinant of toxicity of mineral fibres. On these grounds, a few years ago, the asbestos industry in Québec developed a process to modify the surface chemistry of chrysotile asbestos by fixing phosphorous atoms. The pleuropulmonary fibrogenicity and carcinogenicity of the native and surface treated chrysotile, called chrysophosphate, were tested. Both products initiated similar pulmonary fibrogenicity in rats exposed by inhalation and sheep exposed by injection in the tracheal lobe. Tumour production in rats after long term inhalation or intrapleural injection was not different between chrysotile and chrysophosphate. These findings clearly show that modification of the phosphate surface of chrysotile fibres does not appear to alter the pleuropulmonary activities of the mineral, thus arguing against the earlier contention of less biological activity for chrysophosphate, a contention essentially based upon results of in vitro tests. This study strongly argues for in vivo testing of new fibrous materials before making definite conclusions about their biological activities.
\end{abstract}

\section{(British Journal of Industrial Medicine 1993;50:167-171)}

The biological importance of mineral fibre characteristics such as mineralogical type, fibre size, surface structure, and chemistry, and chemical stability is a subject of considerable research and controversy. Although there is some evidence to relate the biological effects to fibre geometry, ${ }^{1}$ the chemical reactivity of the fibres has also been suggested to be of pathogenic significance. ${ }^{2-9}$ Some chemical alterations of chrysotile undoubtedly alter haemolytic activity, ${ }^{89}$

Cerchar BP 2, 60550 Verneuil en Halatte, France H Daniel, A Wastiaux, P Sébastien

Unité de recherche pulmonaire, CHU Sherbrooke, Quebec, Canada

R Bégin cytotoxicity, ${ }^{9-13}$ and possibly affect carcinogenicity. ${ }^{1314}$

A few years ago, the Société Nationale de l'Amiante (SNA), a research centre for the asbestos industry in Québec, developed a process to modify the surface of chrysotile. The process aimed at fixing phosphorous atoms at the chrysotile surface, by adsorption of $\mathrm{POCI}_{3}$ vapours and thermal treatment. ${ }^{16}$ It was hoped that the phosphorylated chrysotile (chrysophosphate), which had interesting technological properties, would also be less biologically active. ${ }^{16}$ Initial in vitro intraperitoneal and intrapleural studies supported this contention..$^{1314} 17$

Because of the potential benefits for the chrysotile asbestos industry, the SNA provided us with native and treated chrysotile to assess the pulmonary fibrogenicity and carcinogenicity of these two products in animal experiments. Titanium dioxide $\left(\mathrm{TiO}_{2}\right.$; Chronos A/FDZ) was also tested as an inert dust. The three experiments were long term inhalation in rats, intrapleural injection in rats, and injection into the tracheal lobe of sheep.

\section{Methods}

TRACHEAL LOBE IN EXPERIMENTS IN SHEEP

Twenty four sheep weighing $25-40 \mathrm{~kg}$ were used. They were prepared and accustomed to the pulmonary techniques as previously reported. ${ }^{18}$ The flock was divided into three groups of eight sheep exposed either to $100 \mathrm{ml}$ phosphate buffered saline (control group), $100 \mathrm{mg}$ Canadian chrysotile fibres in $100 \mathrm{ml}$ saline (chrysotile group) or $100 \mathrm{mg}$ Canadian $\mathrm{POCI}_{3}$ treated chrysotile fibres in $100 \mathrm{ml}$ saline (chrysophosphate group). Exposures were carried out through bronchoscopic catheterisation and slow infusion in the tracheal lobe.

Bronchoalveolar lavage (BAL) was carried out before exposure (day 0 ) and 12, 24, and 60 days after exposure.

Procedures for BAL and analyses have been described elsewhere. ${ }^{18}$ The BAL effluent was passed through four layers of cheesecloth to remove mucus, and the cells were formed into a pellet by centrifugation. Cells were counted by haemocytometer and cytocentrifuge smears served to identify the cell 
Table 1 Criteria used for grading intensity and profusion of inflammation-fibrotic pulmonary reactions

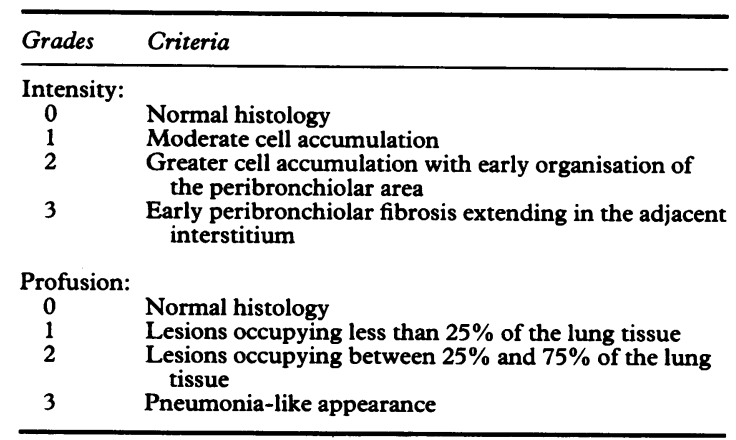

populations recovered with Wright-Giemsa stain. Albumin and fibronectin concentrations in the supernatant fluid were measured by the immunochemical method of Killingworth and Savoy ${ }^{19}$ with a Behring laser nephelometer (Hoerchst Behring, Frankfurt, Germany). For measurement of sheep albumin, specific antiserum raised in rabbits was obtained commercially (Cappell lab inc, Downington, PN). Sheep BAL fibronectin was purified on an affinity column followed by chromatography and antifibronectin antibodies were raised in rabbits as previously reported..$^{20}$ In the supernatant, the activity of lactate dehydrogenase (LDH) and $\beta$-glucuronidase $(\beta-\mathrm{G})$ were measured as previously reported..$^{18}$ All results were expressed per $\mathrm{ml}$ of BAL effluent as albumin did not vary significantly.

At day 60 of the study, all sheep were killed. Nine tissue samples of the tracheal lobe of each sheep were taken for microscopical examination. The samples were processed as routinely done for human lung tissues. In each sample, intensity and profusion of histological changes were graded by comparison with reference lesions. ${ }^{21} 22$ Table 1 presents the grading criteria. For each sheep, a pathological score was obtained by multiplying intensity and profusion grades and averaging the nine values.

\section{INTRAPLEURAL INJECTION IN RATS}

Four groups of $40 \mathrm{Wistar}$ (ICO, IOPS, AF/Han) rats (20 males, 20 females) were used. Weights at the start of the experiment were in the range $240-260 \mathrm{~g}$ for males and $180-200 \mathrm{~g}$ for females. Rats in the control group were housed without injection. Animals in the three other groups received a single intrapleural injection of $2 \mathrm{ml}$ isotonic glucose in which $20 \mathrm{mg}$ of either chrysotile, chrysophosphate, or titanium oxide $\left(\mathrm{TiO}_{2}\right.$; Chronos, Paris, France) had been suspended by ultrasonic treatment.

Animals were observed daily and weighed at monthly intervals. Those in poor condition or losing too much weight were killed in the course of the experiments. One third of the survivors were killed 18 months after the injection, and the rest at 24 months.

At necropsy, the thoracic and abdominal cavities were examined and the left lobe of the lungs was fixed in inflation with $10 \%$ neutral buffered formalin for histological examination. Other lobes of the lungs and organs showing macroscopical changes were also sampled for histology. Three stains were usednamely, haematoxylin and eosin, Gordon and Sweet, and pictosirius. ${ }^{23}$ To differentiate the three histological patterns of mesotheliomas, alcian blue staining was performed at variable $\mathrm{pH} .{ }^{24}$

\section{INHALATION BY RATS}

Three groups of $48 \mathrm{Wistar}$ rats (24 females, 24 males) were exposed in inhalation chambers of 13001 (whole body exposure) for five hours a day, five days a week during a period of 24 months. A modified Timbrell Mark D generator and a cyclone were used to produce clouds of respirable dust. ${ }^{25}$ The gravimetric concentrations of the dust in the chambers were measured daily. The mean concentrations $\left(\mathrm{mg} / \mathrm{m}^{3}\right.$ (SEM)) of respirable dust were $5.8(1.5)$ for chrysotile, $5.8(1.4)$ for chrysophosphate, and 6.2 (3.2) for $\mathrm{TiO}_{2}$. The size distributions of airborne particles were obtained after short term sampling on a membrane filter (Nucleopore, $0.2 \mu \mathrm{m}$ ) and direct examination under a transmission electron microscope. Length measurements of airborne fibres were roughly log normally distributed, and did not differ significantly between chrysotile and chrysophosphate.

The control group was maintained in a similar inhalation chamber during the same period. The rats were observed daily and weighed at monthly intervals. Those in poor condition or losing too much weight were killed in the course of the experiment. All survivors were killed at 24 months. Histopathological examination was similar to that of the intrapleural experiments. Lung inflammation fibrosis was graded as explained for sheep.

\section{STATISTICAL ANALYSES}

Individual measurements were averaged in each group of animals. The standard error of the mean (SEM) was calculated as an index of dispersion. The method of analysis of variance for experiments with repeated measurements on the same subjects was used for BAL measurements in sheep together with the Kruskall-Wallis test. The pathological scores of inflammation fibrosis were analysed by Scheffés procedure. Occurrence of lung tumours in groups of rats was compared using the $\chi^{2}$ test with Yates' correction or Fisher's exact one tailed probability test ${ }^{26} ; \mathrm{p}$ values $<0.05$ were considered significant. 
Table 2 Tracheal lobe experiments in sheep: lung lavage measurements after exposure and pathological score in lung tissue (mean (SEM))

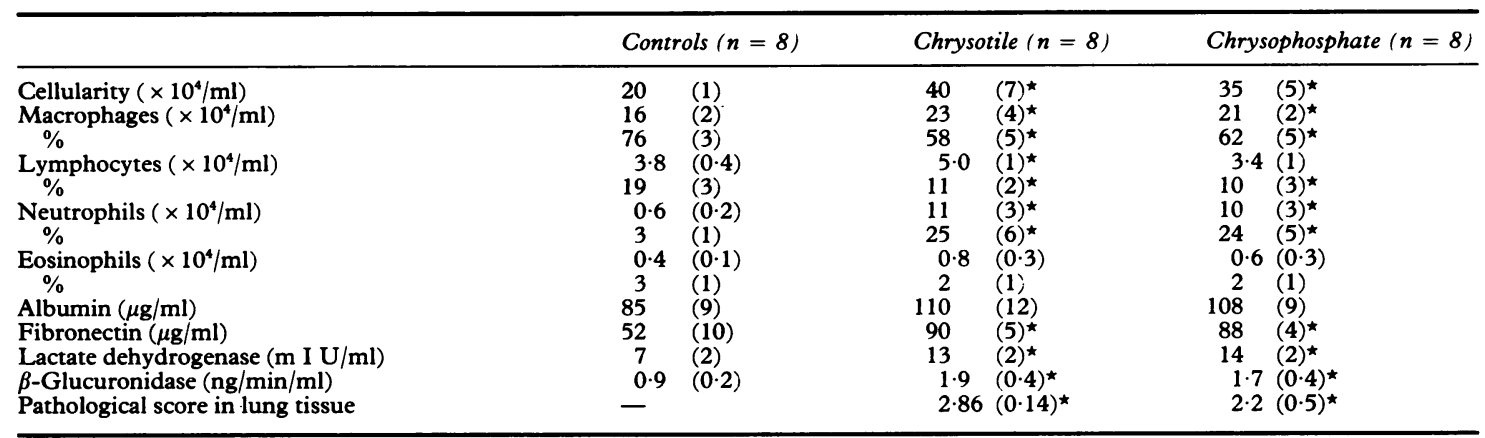

${ }^{\star} \mathrm{p}<0.05$ for exposed $v$ controls.

\section{Results}

TRACHEAL LOBE EXPERIMENTS IN SHEEP

In the control sheep, BAL total cellularity averaged $20(1) \times 10^{4}$ cells $/ \mathrm{ml}$ and did not vary significantly over the two months of the experiments. The differential cell counts also did not vary, with macrophages constituting 76 (3)\%, lymphocyts 19 (3)\%, neutrophils 3 (1)\%, and eosinophils 2 (1)\%. Albumin in BAL averaged $85(9) \mu \mathrm{g} / \mathrm{ml}, \mathrm{LDH} 7.2 \mathrm{ml}$ $\mathrm{U} / \mathrm{ml}$, and B-G $0.85(0 \cdot 16) \mathrm{ng} / \mathrm{min} / \mathrm{ml}$; none of these values varied significantly over time.

The BAL samples in the chrysotile group showed a significant sustained increase in total cells which averaged $40(7) \times 10^{4}$ cells $/ \mathrm{ml}$. Macrophages, lymphocytes, and neutrophils were significantly increased. Mean concentrations of neutrophils were at $\mathbf{1 8}$ times the control values. Albumin was slightly increased at $110(12) \mu \mathrm{g} / \mathrm{ml}(\mathrm{p}>0.05)$. Fibronectin was significantly increase at $90(5) \mu \mathrm{g} / \mathrm{ml}(\mathrm{p}<0.05)$ and this increase remained significant after correction for albumin. The enzyme $\mathrm{LDH}$ in the BAL supernatant was increased at $13(2) \mathrm{ml} \mathrm{U} / \mathrm{ml}$ $(\mathrm{p}<0.05) ; \beta-\mathrm{G}$ was increased at $1.9(0.4) \mathrm{ng} / \mathrm{min} / \mathrm{ml}$ $(\mathrm{p}<0.05)$.

In the chrysophosphate group, all BAL measurements were increased but at levels that did not differ significantly from those in the chrysotile group. In the absence of significant change with time in the post-exposure period, results were averaged in each group and compared (table 2).

The lungs of the control sheep, were normal at histopathological examination. A diffuse peribronchiolar fibrosing alveolitis was found in the chrysotile group. It was extending in the adjacent lung tissue as previously found with chrysotile tested in that model. ${ }^{18}$ The mean pathological score was 2.86 $(0 \cdot 14)$. In the chrysophosphate group, similar lesions were present, although somewhat less intense. The mean pathological score was $2.2(0.5)$ lower but not significantly different from that in the chrysotile group.
INTRAPLEURAL INJECTION IN RATS

Table 3 gives the mortality in each group. It was always higher for rats injected with fibre, especially chrysotile in the period 18-24 months. In the chrysotile, chrysophosphate, and $\mathrm{TiO}_{2}$ groups, an invasive thoracic tumour was present in $56.5 \%$, $24 \cdot 4 \%$, and $2 \cdot 8 \%$ of the animals respectively. A total of 28 mesotheliomas was produced. Table 3 reports their distribution by test group and period. One mesothelioma occurred in the $\mathrm{TiO}_{2}$ group; none in the control group. The total numbers of mesotheliomas in the chrysotile and chrysophosphate groups were respectively 16 and 11 .

In each of the three groups of rats exposed to dust particles, the proportion of animals with benign hyperplasia of the mesothelial lining averaged $8.5 \%$. More than $90 \%$ of the animals exposed to fibres developed pleural thickening, with no difference between the chrysotile and chrysophosphate groups.

No primary pulmonary carcinoma was present in any of the animals examined. In $17 \%$ (chrysotile) and

Table 3 Mortality and occurrence of mesothelioma in intrapleural injection experiments in rats

\begin{tabular}{|c|c|c|c|c|c|}
\hline & \multicolumn{5}{|c|}{ Months after intrapleural injection ${ }^{\star}$} \\
\hline & $<18$ & 18 & $18-24$ & 24 & All \\
\hline \multicolumn{6}{|c|}{ Number of rats dead or killed: } \\
\hline Controls & 2 & 14 & 3 & 12 & $31+$ \\
\hline $\mathrm{TiO}_{2}$ & 3 & 14 & 5 & 14 & $36 t$ \\
\hline Chrysotile & 6 & 13 & 16 & 5 & 40 \\
\hline Chrysophosphate & 6 & 12 & 8 & 14 & 40 \\
\hline \multicolumn{6}{|c|}{ Number of rats with mesothelioma: } \\
\hline Controls & 0 & 0 & 0 & $\mathbf{0}$ & 0 \\
\hline $\mathrm{TiO}_{2}$ & 0 & 0 & 0 & 0 & 1 \\
\hline Chrysotile & 2 & 3 & 10 & 1 & 16 \\
\hline Chrysophosphate & $\overline{1}$ & 3 & 2 & 5 & 11 \\
\hline
\end{tabular}

$\star<18=$ Early mortality before killing at month $18 ; 18=$ killed at month $18 ; 18-24=$ mortality between killing at month 18 and killing at month $24 ; 24=$ killing at month 24 .

†Some animals died in circumstances such that lungs were not available for examinaiton. 
Table 4 Mortality and occurrence of tumours in inhalation experiments in rats

\begin{tabular}{|c|c|c|c|}
\hline & $\begin{array}{l}\text { Animals } \\
\text { dead before } \\
\text { month } 24\end{array}$ & $\begin{array}{l}\text { Animals } \\
\text { killed at } \\
\text { month } 24\end{array}$ & $A l l^{\star}$ \\
\hline \multicolumn{4}{|c|}{ Number of rats dead or killed: } \\
\hline Controls & 3 & 36 & 39 \\
\hline $\mathrm{TiO}_{2}$ & 10 & 34 & 44 \\
\hline Chrysotile & 7 & 36 & 43 \\
\hline Chrysophosphate & 13 & 29 & 42 \\
\hline \multicolumn{4}{|c|}{ Number of rats with adenomas: } \\
\hline Controls & 0 & 1 & 1 \\
\hline $\mathrm{TiO}_{2}$ & $\mathbf{0}$ & 1 & 1 \\
\hline Chrysotile & 0 & 4 & 4 \\
\hline Chrysophosphate & 1 & 3 & 4 \\
\hline \multicolumn{4}{|c|}{ Number of rats with adenocarcinomas: } \\
\hline Controls & $\mathbf{0}$ & $\mathbf{0}$ & 0 \\
\hline $\mathrm{TiO}_{2}$ & $\mathbf{0}$ & 0 & 0 \\
\hline Chrysotile & $\mathbf{0}$ & 1 & 1 \\
\hline Chrysophosphate & $\mathbf{0}$ & 2 & 2 \\
\hline \multicolumn{4}{|c|}{ Number of rats with squamous carcinomas: } \\
\hline Controls & 0 & 0 & 0 \\
\hline $\mathrm{TiO}_{2}$ & $\mathbf{0}$ & $\mathbf{0}$ & 0 \\
\hline Chrysotile & $\mathbf{0}$ & 0 & 0 \\
\hline Chrysophosphate & $\mathbf{0}$ & 3 & 3 \\
\hline \multicolumn{4}{|c|}{ Number of rats with lung tumours: } \\
\hline Controls & $\mathbf{0}$ & 1 & 1 \\
\hline $\mathrm{TiO}_{2}$ & $\mathbf{0}$ & 1 & 1 \\
\hline Chrysotile & $\mathbf{0}$ & 5 & 5 \\
\hline Chrysophosphate & 1 & 8 & 9 \\
\hline
\end{tabular}

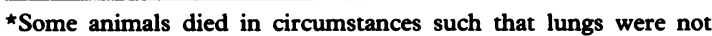
available for examination.

$7 \%$ (chrysophosphate) of the rats exposed to fibre inflammatory granulomas were present. Granulomas were surrounded by collagen fibres and had a necrotic, sometimes calcified core. No granuloma was present in the $\mathrm{TiO}_{2}$ group.

\section{INHALATION BY RATS}

Table 4 indicates the mortality before month 24 . The highest rate $(40 \%)$ of premature death was recorded in the chrysophosphate group. This excess was due to interstitial nephritis diagnosed as chronic progressive nephritis.

Benign tumours (adenomas) and malignant tumours (adenocarcinomas and squamous carcinomas) were found at histological examination. Table 4 presents their distribution in the four groups. Rats exposed to fibres developed more tumours than the controls. The difference was significant for the chrysophosphate group. The occurrence of tumours was not statistically different for chrysotile and chrysophosphate. No mesothelioma was detected.

In terms of inflammatory lesions, the control rats and the exposed to $\mathrm{TiO}_{2}$ had essentially normal lungs, apart from a slight excess of alveolitis in the $\mathrm{TiO}_{2}$ group. Most of the animals exposed to fibres had alveolitis, sometimes associated with alveolar proteinosis. Both interstitial and peribronchiolar fibrosis were found in animals exposed to fibres, often associated with alveolar epithelial hyperplasia or metaplasia. The severity of these lesions was comparable between the chrysotile and chrysophosphate groups. Mean pathological scores in the chrysotile, chrysophosphate, and $\mathrm{TiO}_{2}$ groups were respectively $2.08(1.0), 1.96(1.0)$, and $0.34(0.2)$.

\section{Discussion}

This report presents the results of three sets of experiments that were conducted to evaluate the relative toxicity of native chrysotile fibres and $\mathrm{POCI}_{3}$ modified fibres. These studies were carried out after earlier in vitro and in vivo studies had shown a relatively reduced cytotoxicity ${ }^{13-17}$ and a reduced carcinogenicity for the chrysophosphate in the rat intraperitoneal injection model. ${ }^{14}$

The present experiments were conducted in established animal models known to reproduce fibre related diseases. The sheep model reproduces the fundamental lesions of asbestosis ${ }^{18212227}$; the rat intrapleural model is often used for studying the potency of fibres to induce mesothelioma ${ }^{28-30}$; the rat inhalation model is a well recognised model for asbestosis and lung carcinomas. ${ }^{3132}$

In our study, chrysophosphate and chrysotile exhibited similar pulmonary fibrogenicity in sheep and rats. During the final six months of the intrapleural rat experiment, mortality was higher in the chrysotile group and related to histologically identified mesotheliomas. The incidence of such tumours was lower in the chrysophosphate group than in the chrysotile group but the difference was not significant. Similar results were obtained by others using the intraperitoneal test. ${ }^{14}$ Our long term inhalation experiments, however, did not show less pulmonary carcinogenicity for chrysophosphate. The incidence of pulmonary carcinomas, especially squamous carcinomas, was greater with chrysophosphate than chrysotile, but again the difference was not statistically significant.

Previous attempts at modifying the chemistry or surface of asbestos fibres have been able to document some associated biological changes. Leaching the magnesium of chrysotile reduces its toxicity in vitro, whereas the same process enhances the toxicity of crocidolite. ${ }^{5}$ Haemolytic activity of asbestos fibres can be significantly reduced by serum, ethylenediaminetetraacetic acid (EDTA), and several other compounds, including metal oxides and metal micelles. ${ }^{812}$ Two independent studies have shown that $90 \%$ of magnesium depleted chrysotile asbestos has significantly reduced carcinogenicity, at least as determined by the intrapleural injection model. ${ }^{34} 35$ All these data strongly suggest that, as well as fibre size, surface chemistry can be a determinant of some biological activity.

Our results clearly show that the particular surface modifications induced by $\mathrm{POCl}_{3}$ treatment were 
ineffective in reducing the long term fibrogenicity and carcinogenicity of chrysotile in experimental animals. To reconcile the previous studies on chrysophosphate with the present observations, it must be considered that in vitro and intraperitoneal models may not always reflect entirely and completely the in vivo intrapleuropulmonary biological events and thus may give different results. Also it may be that in our studies the $\mathrm{POCl}_{3}$ treatment did not reach all of the fibrils of chrysotile within the bundles often present in the raw chrysotile or chrysophosphate materials (B Pathak and P Sébastien, personal communication). Treatment with $\mathrm{POCl}_{3}$ could have been more effective in the materials used in previous studies.

This study was supported in part by CERAM-SNA inc, an affiliate of Société Nationale de l'Amiante, Sherbrooke, Canada.

Requests for reprints to: Raymond Bégin MD, Unité de recherche pulmonaire, CHU Sherbrooke, QUEBEC, Canada J1H 5N4.

1 Wagner JC, ed. Biological effects of mineral fibres. Vols 1 and 2 Lyon: International Agency for Research on Cancer. 1980.

2 Jaurand MC, Bignon J, Sebastien P, Goni J. Leaching of chrysotile asbestos in human lungs. Environ Res 1977;14: 245-54.

3 Koyama N, Kawai K, Aita S, Suzuki M, Hayashi JH. Quantitative chemical analysis of chrysotile fibrils in lung tissue by analytical electron microscopy. Ind Health 1977;15:159-71.

4 Morgan A, Davies P, Wagner JC, Berry G, Holmes A: The biological effects of magnesium-leached chrysotile asbestos. British Journal of Experimental Pathology 1977;58:465-73.

5 Jaurand MC, Magne L, Boulmier JL, Bignon J. In vitro reactivity of alveolar macrophages and red blood cells with asbestos fibers treated with oxalic acid, sulphur dioxide and benzo-3,4-pyrene. Toxicology 1981;21:323-42.

6 Spurny KR. Measurement and analysis of chemically changed mineral fibers after experiments in vitro and in vivo. Environ Health Perspect 1983;51:343-55.

7 Sara EA, Brown RC, Evans CE, Hoskins JA, Simpson CF. Interaction of amosite and surface modified amosite with a V79-4 (chinese hamster lung) cell line. Environ Health Perspect 1990;85:101-5.

8 Macnab G, Harington JS. Haemolytic activity of asbestos other mineral dusts. Nature 1967;214:522-3.

9 Schnitzer RJ, Pundsack F. Asbestos hemolysis. Environ Res 1970;3:1-13.

10 Hahon N, Vallyathan V, Booth JA, Sepulveda MJ: In vitro biologic response to native and surface-modified asbestos. Environ Res 1986;39:345-5.

11 Vallyathan N, Hahon J, Booth D, Schwegler M, Sepulveda MJ. Cytotoxicity of native and surface-modified asbestos. In: Beck EG, Bignon J, eds. In vitro effects on mineral dusts. Berlin: Springer-Verlag, 1985:159-65 (NATO ASI Series, vol G3).

12 Flowers ES, McLean V. New chemical process for asbestos treatment. Asbestos 1992;64:5-10.

13 Dunnigan J, Nadeau D, Paradis D, et al. Cytotoxic and hemolytic effect of native and chemically modified chrysotile.
Proceedings of the 4th international conference on asbestos, Turin, 1980:II ;748-72.

14 Maltoni C, Minardi F. Recent results of carcinogenicity bioassaye of fibers and other particulate materials. Ann N Y Acad Sci 1988;534:754-65.

15 Menard H, Noel L, Khorami J, Jouve JL, Dunnigan J. The adsorption of polyaromatic hydrocarbons on natural and chemically modified asbestos fibers. Environ Res 1986;140: 84-91.

16 Lalancette JM, Dunnigan J. Novel phosphated asbestos fibers. US Patent No 4:356-357, 26 Oct 1980.

17 Forget G, Lacroix MJ, Calvert R, Sirois P. Measurement of beta-glucoronidase in effluent of perifused alveolar macrophages challenged with chemically modified chrysotile asbestos. Inflammation 1984;8:123-41.

18 Bégin R, Massé S, Rola-Pleszczynski M, Drapeau G, Dalle D: Selective exposure and analysis of the sheep tracheal lobe as a model for toxicological studies of respirable particles. Environ Res 1985;36:389-404.

19 Killingsworth LM, Savory J: Maunal nephelometric methods for immunochemical determination of immunoglobulins IgG, IgA and IgM in human serum. Clin Chem 1972;18:335-9.

20 Bégin R, Martel M, Desmarais Y, Drapeau G, Boileau R, RolaPleszczynski M, Masse S. Fibronectin and pro-collagen 3 levels in broncholveolar lavage of asbestos-exposed human subjects and sheep. Chest 1986;89:237-43.

21 Bégin R, Massé S, Bureau MA: Morphologic features and function of the airways in early asbestosis in the sheep model. Am Rev Respir Dis 1982;126:870-6.

22 Bégin R, Massé S, Sébastien P, et al. Asbestos exposure and retention as determinants of airway disease and asbestos alveolitis. Am Rev Respir Dis 1986;134:1176-81.

23 Martin JC, Daniel H. L'expérimentation dans l'étude des maladies pulmonaires par poussières. Ann Med Reims 1969; 6:95-104.

24 Lé Bouffant L, Daniel-Moussard H, Martin JC, Charbonnier J, Letort M, Policard A. Méchanismes de I'inhibition du pouvoir fibrogène des poussières de silice par des substances minérales. Rôle des états de surface. Arch Mal Prof 1969;30:305-10.

25 Lé Bouffant $L$. Étude quantitative de l'épuration pulmonaire chez le rat. Comparaison entre poussières inertes et poussières nocives. In: Davies $\mathrm{CN}$, ed. Inhaled particles and vapours. Oxford: Pergamon Press, 1961:369-83.

26 Bégin R, Massé S, Rola-Pleszczynski $M$, et al. The lung biological activity of american attapulgite. Environ Res 1987; 42:328-39.

27 Snedecor GW, Cochran CW. Statistical methods. Ames: Iowa State University Press, 1967.

28 Wagner JC, Berry G. Mesotheliomas in rats following inoculation with asbestos. Br J Cancer 1969;23:567-81.

29 Wagner JC, Berry G, Timbrell V. Mesotheliomas in rats following inoculation with asbestos and other materials. $\mathrm{Br} J$ Cancer 1973;28:173-85.

30 Burger BF, Engelbrecht FM. The biological effects of long and short fibres of crocidolite and chrysolite A after intrapleural injection into rats. South African Med J 1970;44:1268-70.

31 Wagner JC, Berry G, Skidmore JW, Timbrell V. The effects of the inhalation of asbestos in rats. Br J Cancer 1974;29:252-69.

32 Davis JMG, Beckett ST, Bolton RE, Collings P, Middleton AP. Mass and number of fibres in the pathogenesis of asbestosrelated lung disease in rats. Br J Cancer 1978;37:673-88.

33 Jaurand MC, Renier A, Gaudichet A, Kheunang L, Magne L, Bignon J. Shoft term tests for the evaluation of potential cancer risk of modified asbestos fibers. Ann NY Acad Sci 1988;534:751-4.

34 Morgan A, Davies P, Wagner JC, Berry G, Holmes A. The biological effects of magnesium-leached chrysotile asbestos. Br J Exp Path 1977;58:465-73.

35 Monchaux G, Bignon J, Jaurand MC, et al. Mesotheliomas in rats following inoculation with acid-leached chrysotile asbestos and other mineral fibers. Carcinogenesis 1981;2:229-36.

Accepted 13 April 1992. 